\title{
System Design for an Online Social Networking App with a Notification and Recommender System to Build Social Capital in a University Setting
}

\author{
Daniel Raymond Trí Đặng Firpo \\ Claremont Graduate University \\ firpod85@gmail.com
}

Kittisak Sirisaengtaksin

Claremont Graduate University

kittisakz@hotmail.com

\author{
Sonya Zhang \\ Cal Poly Pomona \\ xszhang@,cpp.edu
}

\author{
Lorne Olfman \\ Claremont Graduate University \\ lorne.olfman@,cgu.edu
}

\author{
Joe Tawan Roberts \\ Claremont Graduate University \\ joe.tawan.roberts@gmail.com
}

\begin{abstract}
Social capital in higher education commuter institutions may be declining because fewer students remain on campus. Social capital is the network of relationships in a group. Higher social capital is derived from broader and more complex networks. Social networks can grow because members who belong to a particular group possess a sense of community. If students spend less time on campus, their sense of community may decrease, because they would be less likely to participate in the community. This puts Higher Ed commuter institutions at a disadvantage in terms of generating and maintaining social capital. We investigate the possibility to counter this disadvantage by actively promoting participating in an Online Social Network (OSN); specifically, with the use of a Notification and Recommender System (NARS) in an OSN via a mobile platform. Our results suggest that introducing a purposefully designed OSN has the potential to facilitate creation of structural and relational social capital, but that it might not have an effect on cognitive social capital.
\end{abstract}

\section{Introduction}

This study details the novel system design of a mobile social media application for a higher education institution to address the following problems: low sense of community, lack of social capital, and the inability of many students to harness what social capital currently exists in their institution. Higher Ed commuter institutions may have lower- social capital because fewer students stay on campus. Social capital is the network of relationships in a group. If students spend less time on campus, their sense of community - the feeling that one is part of a social structure - may decrease because they are less able to participate in the network. This is an especially timely concern, given the recent trend in colleges and universities towards online learning, potentially increasing the number of students who might participate in a scholarly community with limited access for accruing the social capital benefits of that participation.

From the perspective of constructivism - an experiential learning theory - social capital is important because if it increases, then so too does the capacity of the community to generate intellectual capital [38]. Online Social Networks (OSN) can create virtual campus presence. A sense of community, affiliation, and togetherness are prerequisites for an intellectual community that directs social norms towards knowledge sharing and knowledge creation [9]. Trust, social relationships, and mutual interdependencies must be built and maintained to allow community members to collaborate effectively [32]. Informal communication plays a critical role in effective collaboration. It provides groups of individuals who have no prearranged agenda with rich interactive content, and an informal language [30]. In other words, building community is a prerequisite for successful collaborative knowledge construction, and a more productive student and alumni network.

According to [37], these new forms of humancomputer social interaction need to be addressed before society can create an effective online community. This is especially true for technologies that facilitate social networking. Mobile web technology has the potential to extend the university's sense of community beyond its physical buildings to ensure that its level of social capital does not decrease as its geographical reach increases.

This study focuses on the design of a recommender system in an OSN to determine what potential effects a 
mobile application that uses recommendations can have on scholarly community. The design of this artifact serves as a starting point for exploring the following questions: How would it affect the sense of community amongst an OSN? How would it affect the level of social capital in an alumni community? How would it affect the ability of students and alumni to harness the social capital that exists in their social network?

Previous studies suggest that a properly deployed IT artifact can strengthen the sense of community in a higher learning institution [41], that a strong sense of community will lead to an increase in social capital in a scholarly community [52], and that this could further strengthen the intellectual output of that community [55].

Our study's design artifact, titled "Claremont Connection," was designed to connect alumni and facilitate professional transdisciplinary networking between alumni and current students at a Higher Ed institution, and to enhance the value in its social networks. The app was designed to facilitate the creation of new connections and strengthen existing ones, which could in turn increase the social capital of the alumni and students. It enables alumni to find other community members with similar research interests or complementary skills, and to provide career opportunities or advancement for current students. A Notification and Recommender System (NARS) sends push notifications to users, notifying them of other students or alumni with similar research interests, or of professional opportunities based on matched skillsets. Increased access to social resources is beneficial to the career success outcomes of community members, because this increases the opportunity for career sponsorship, and facilitates better access to information and resources [48]. The design artifact can be generalized as an Information Systems Design Theory (ISDT) that can be used by other higher learning institutions to create customized versions of the app [58].

Previous research on recommender apps focused mainly on ways to improve accuracy, ignoring the effect of the app itself on the users, or the social media system as a whole [54]. Additionally, previous research on push notification systems focused mainly on their ability to affect users' motivation to participate [41]. Unlike those previous studies, this study focuses on the effect of the design artifact on the entire community in which it is deployed.

Though websites such as ResearchGate have similar functions, our novel system design focuses on a customizable app to build social capital within a single institution, with a high level of artifact mutability such that it can be modified and deployed at other Higher
Ed institutions with similar effect. Furthermore, whereas other universities have apps that provide similar services, their goals are usually geared more towards enabling simple social networking $[2,16,40]$, whereas this study's artifact aims to facilitate social networking with a stronger emphasis on academic, scholarly, and professional networking.

\section{Literature Review}

\subsection{Social Capital}

Social Capital was the key kernel theory for this study. Social capital is "the sum of the actual and potential resources embedded within, available through, and derived from the network of relationships possessed by an individual or social unit;" the goodwill available to groups or individuals [33]. Its source lies "in the structure and control of the actors' relations," and its effects "flow from the information, influence, and solidarity it makes available to the actor" [3]. Before the dawning of social capital research, more attention had been paid to the development of Human Capital: how individuals obtain, develop, and nurture the skills and knowledge necessary to be productive in a competitive labor market. However, throughout the 20th century, social capital theory gained acceptance from sociologists and economists as a means of explaining the differences in individual success besides through individual characteristics alone [14]. Social capital concerns the value of social networks, along the colloquial wisdom that "more people get their jobs from whom they know, rather than what they know," [46] or; the goodwill that others have towards each other is itself a valuable resource [3].

Social capital is a measurement of the value of concrete personal relationships and the network of social relationships that shapes individual behavior and influences individual and societal growth [36]. The central concept is that relationships matter, and social networks themselves are a valuable asset: interaction allows people to build community and establish norms of reciprocity and create a sense of membership and belonging [18]. It turns trust between individuals into trust between strangers, and trust in a broad fabric of social institutions - a "shared set of values, virtues, and expectations within society as a whole" [6]. Unlike other forms of capital, social capital is primarily created and disseminated through cultural mechanisms, such as cultural tradition or religious institutions [19].

Social capital benefits a community in two different ways: through allocative efficiency and through adaptive efficiency [33]. Allocative efficiency is the extent to which social capital increases the proficiency 
of action [35] or decreases the costs of transactions [38]. Adaptive efficiency [19,27,38] refers to the creativity and learning social capital delivers in encouraging "cooperative behavior, thereby facilitating the development of new forms of association and innovative organization" [33].

Prior studies have demonstrated that social capital facilitates resource exchange and innovation [22,24], and the creation of intellectual capital $[25,33]$. Studies have also demonstrated a positive relationship between social capital and knowledge integration and transfer $[43,44]$. Other studies demonstrated that high levels of social capital are related to group cohesiveness, eventually supporting collective behavior [62].

Of concern to Higher Ed institutions, in communities with high social capital, members have an easier time finding jobs and advancement opportunities [21,31] and there is a richer pool of recruits for organizations and research groups [17]. Social capital directly benefits the transfer of knowledge within and between communities [3,33], with organizational culture, learning capacity, and intention as the prime knowledge transfer processes [12,34,43].

Social Capital is a multi-dimensional concept, comprised of attributes such as trust, rules and norms, types of social interaction, network resources, etc.. Each attribute contributes to the whole definition of the concept without fully capturing the concept on its own [23].

[33] developed a model that hypothesized the relations between the different dimensions of social capital, and the process through which this fosters the creation of intellectual capital. It has since become one of the most widely used conceptualizations of social capital [44]. [33] define three different dimensions of social capital: Structural, Relational, and Cognitive. Structural social capital refers to the shape of a social network: layout and overall pattern of connections between actors, i.e. "who you reach and how you reach them" [11]. The structural dimension is comprised of network ties, network configuration, and appropriable organization. Relational social capital refers to the assets created and leveraged through these connections, and the relations that community members have that affect their behavior. The relational dimension is comprised of norms, obligations and expectations, member identification, and the level of trust in a community. Cognitive social capital refers to "those resources providing shared representations, interpretations, and systems of meaning among parties." The cognitive dimension is comprised of a community's shared language and codes, and its shared narratives [33].

\subsection{Online Social Networks and Social Capital}

There has been a wide range of scholarly opinion on use of Online Social Networks (OSN) and social capital [13]. [38] suggested that by "individualizing" leisure time, use of the Internet decreases social capital. On the other hand, [60] concluded that use of the Internet can supplement social capital by strengthening and extending the capital that already exists in face-to-face and telephone contacts. Other studies [56] have linked internet use to both increases and decreases in social capital.

Studies have shown the importance of social media-based linkages in the formation of weak ties, a key factor in fostering bridging social capital [16]. Social networking technology is well suited to creating and maintaining such weak ties easily, with little effort required from the community members. As such, social networking sites can potentially increase the number of weak ties community members can form and maintain $[15,16]$.

Users of OSNs differ from users of the Internet in general in that OSNs are bound together by shared goals, needs, interests, and practices. In a healthy OSN, the social capital is strong enough to motivate members to overcome barriers of the knowledge sharing process, even - or especially - when no explicit reward is guaranteed [13]

Since network ties and hierarchy are the major factors of structural social capital, an OSN can build this form of social capital directly by connecting community members with each other across the digital medium [44]. This effect can be further enhanced with the use of a recommender system [54].

Several studies have shown that online communications have a positive effect on users' trust, as well as their level of participation in community life $[28,29,42]$. Additionally, studies have demonstrated positive links between different motives for internet use (e.g., gathering information, communication, and recreation) and social capital [5,39,50,57].

\subsection{Notification and Recommender Systems}

Previous research $[51,54]$ has suggested adding a recommender system to an OSN can aid communication and foster new connections. A recommender system presents users with information and automated assistance in order to better decide what products or services to choose; the recommendations of these systems are often based on user evaluations via some means of rating or ranking these products or services [47]. Recommender systems can help users with the problem of information overload, since these 
evaluations or ratings can help users sift through daunting amounts of data in a timely manner to find products, services, or content relevant to the user $[1,45]$. Recommender systems not only mimic subject matter experts, they can also take the user's preferences into account [10].

Recommender systems are most commonly used in e-commerce, but they have seen use in collaborative and e-learning settings $[8,10]$. Although recommender systems are more commonly used to recommend products to individuals [53], [4] argue that recommending other users is no different than recommending products: i.e., a social matching system is still a kind of recommender system since it address the issue of information overload. Recommendations are often features of OSNs or online marketplaces, e.g. the "People you may know" feature in Facebook, or recommendations and wish lists as seen in sites like Amazon.com. Furthermore, prior studies [54,63] have demonstrated the use of recommender systems in Higher Ed contexts for social matching. [63] proposed a recommender system to foster connections between users with similar research interests, and [54] used a system to match users who rated intellectual content similarly. However, neither of these systems was mobile-based. A mobile platform-based OSN could have an advantage over traditional platforms as their convenience, high portability, and more constant presence within the users' vicinity can lead to faster response times [26]. One reason why is the higher efficiency of Push Notifications on mobile platforms. One advantage of using push notifications in a mobilebased platform is the increased efficiency with which users may be presented with relevant information. [51] looked at push notifications in a Higher Ed setting, finding that when used in course discussions, a Notification and Recommender System (NARS) can increase awareness of other community members' posted content, while simultaneously reducing information overload.

\section{Methodology}

The purpose and scope of this study is to develop a mobile app that could improve the scholarly community of a Higher Ed institution. Its constructs are an OSN, a recommender system, and a push notification system. Regarding principles of form and function, through an OSN, users can update their profiles and post opportunities for other users. Based on pre-defined triggers and criteria, the design artifact will push recommended social connections or relevant opportunities to users. The app was designed with artifact mutability in mind. That is, we focused on the degree to which the artifact can be modified to accommodate the state of any environment it is deployed in (i.e. different higher learning environments) while still remaining theoretically sound. This study set out to explore how novel system designs could address the following propositions:

- P1: A Mobile OSN with NARS could yield higher levels of sense of community than a traditional OSN.

- P2a: A Mobile OSN with NARS could yield higher levels of structural social capital than a traditional OSN.

- P2b: A Mobile OSN with NARS could yield higher levels of relational social capital than a traditional OSN.

- P2c: A Mobile OSN with NARS could yield higher levels of cognitive social capital than a traditional OSN.

- $\quad$ P3: A Mobile OSN with NARS could yield greater exchange and combination of knowledge than a traditional OSN.

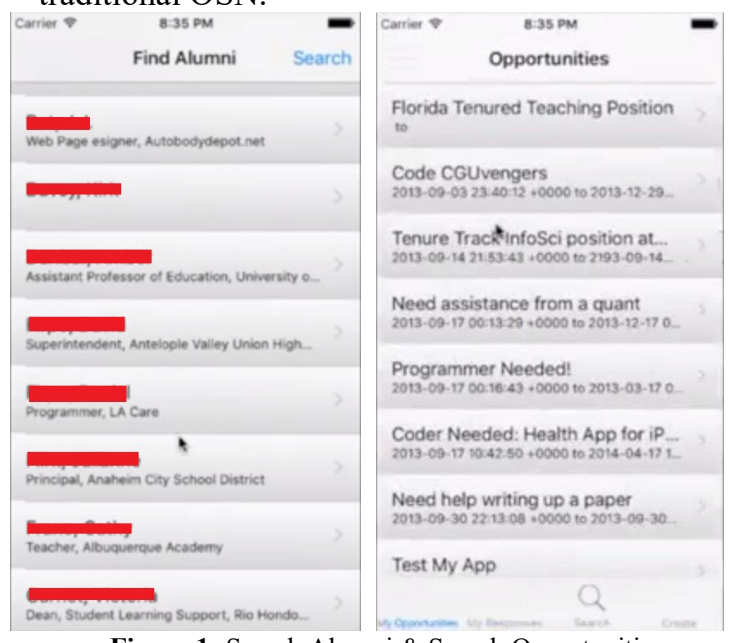

Figure 1: Search Alumni \& Search Opportunities

Social capital theory is the justificatory knowledge that informs the artifact design. Regarding principles of implementation, the design process followed [49]'s action design research methodology. The expository instantiation is an implementation of the design artifact through which the hypotheses can be explored. The name "Claremont Connection" was chosen for the design artifact.

The main constructs for the design artifact were user profiles, a space to post and respond to opportunities, and the recommender system. User profiles were a way for students and alumni to create, update, and maintain their own electronic profiles and share news of their academic output or career achievements with each other. Users were also able to find others within the community based on research 
interests and skills. For the purposes of this app, "Opportunities" refer to any open solicitation for collaboration on a research project or group project (e.g., "I'm working on a research project that involves the development of a mobile app. I'm looking for a student/alum with experience in software development," "I'm working on a paper for an upcoming conference, and I am looking for co-authors with a background in qualitative methods."), or to any posting of an open position (e.g., "There's an adjunct faculty position open at my University," "My company is hiring, and they are specifically looking for potential hires with experience writing grant proposals."). The opportunities page was a way for students and alumni to solicit help on research projects, to share teaching or job openings with the community, and a way for interested students or alumni to respond to these opportunities. The recommender system was a way to broadcast information regarding relevant User Profiles and Opportunities to other users. There were four kinds of push notifications that the app would send out:

\section{Recommending Peers}

a. When any user adds to or edits their "Skills and Research Interests" section of their Profile: " $<$ User $>$ is also interested in $<$ Skill or Research Interest $>$.'

b. When any user sent a message to a fellow community member after clicking the "Contact" button of the User Profile page:

"<User> would like to contact you."

\section{Recommending Opportunities}

a. Whenever an opportunity was posted where there was a match between another users' listed Skills or Research Interests and those required by the posted Opportunity: " $<$ Opportunity Name $><$ User $>$ has just posted an Opportunity that requires expertise in <Skill or Research Interest>."

b. When any user responds to another posted Opportunity: "<User $>$ has just responded to $<$ Opportunity Name>."

The app and the survey instruments were pilot tested during five focus group sessions over a fourweek period after coding on the app had been frozen.

To explore how our system design would address our propositions, we conducted five focus groups to better understand what aspects of the design artifact had potential (or which aspects did not). Back-end analytics were used to see how focus group participants used the app. The five focus groups had five to six participants each.

Focus group sessions lasted around two hours each. A short description of the design artifact and its purpose was provided to participants. Participants would then be walked through the main features of the app, followed by a period of free use, and then group discussion afterwards. Group discussion sessions were semi-structured. Descriptive questions were asked, where participants would have to explain their answers in some detail, providing a greater understanding than what could be derived from survey data alone.

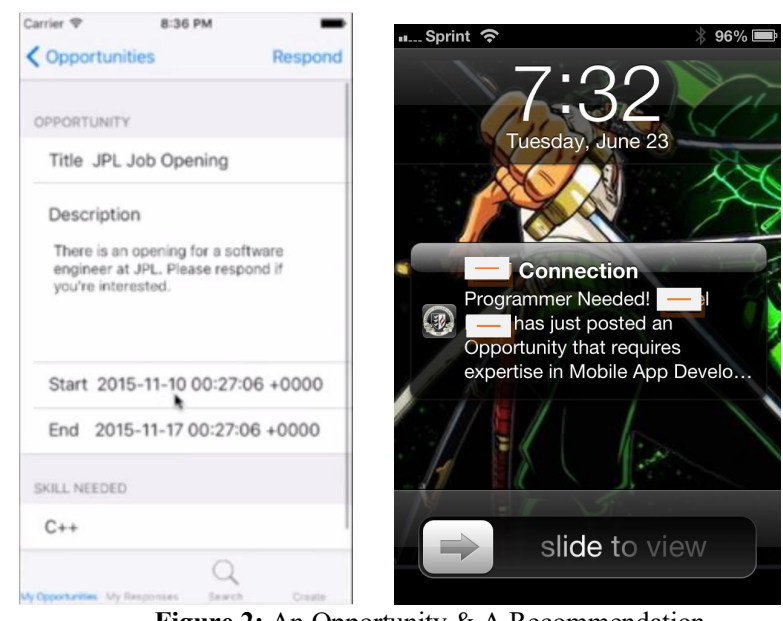

Figure 2: An Opportunity \& A Recommendation

Group discussion among participants was encouraged so each participant could voice his or her opinions. These opinions could help explain usage patterns that appeared counterintuitive or conflicting by exploring the processes at work in the community or why a community member felt a certain way.

The population for this study included students from a Higher Ed institution. Focus group participants were recruited based on a wide range of demographic characteristics such as age, gender, occupation, alumni versus current students, etc. Data was collected late in the Spring 2016 semester.

Focus Group discussion topics were derived from survey instrument created by [13] to measure social capital, along with additional discussion topics adapted from measures used by [57] and [59].

Combination and Exchange of Knowledge questions were also derived from the Quality of Knowledge survey instrument developed by [13].

A push notification (a peer recommendation based on shared research interests) would automatically trigger early in the focus group sessions to ensure that each participant was exposed to the notification and recommendation system (NARS). That way, even if a participant had not met any of the normal conditions that would trigger a push notification, he or she would still be aware of the feature, its interface, and how it works. Additionally, the NARS and its function was explained to each participant, and further discussed in a group setting with other participants who did receive 
push recommendations. Thus, even students who had not used the feature were still indirectly exposed to it.

\section{Summary of Findings}

\subsection{Sense of Community}

Regarding Proposition 1 ("A Mobile OSN with NARS can yield higher levels of sense of community"), a clear majority of participants had a positive attitude towards the design artifact as an OSN. Suggested improvements to the artifact as an OSN include implementing a Newsfeed, implementing a Map feature to find alumni in the user's vicinity, maintaining a strong administrative presence, and allowing casual social networking. A majority of participants had a positive attitude towards the design artifact's Push Notification and Recommender System. However, many of those who expressed positive attitudes towards the NARS did so with the caveat that they would like to have the ability to filter or turn off notifications. Suggested improvements to the design artifact's NARS include the ability to filter or turn off notifications, recommendations based on things besides shared skills (e.g. country of origin), the ability to endorse other users, and the addition of a Word Bank. This suggests that such an app has the potential to foster a sense of community. Most of the suggested features put forth by participants fell into two different categories: having more administrative oversight and enabling support for casual social networking as well as professional networking.

Administrative oversight tied into the need for a critical mass of users or regularly updated content in order to reach a self-sustaining community. Students expressed they would be reluctant to participate if they did not believe there was an adequate baseline of activity taking place in the OSN, citing the concern as to whether they would receive a prompt or timely response to any opportunity they post via the app. Many participants suggested allowing the university itself to post opportunities and events through the app, as a way to maintain this baseline of new content. This reaffirms findings of similar studies that an administrative presence to create new content on a regular basis is necessary to generate motivation among community members to participate in an OSN $[41,54]$

Although [61] suggested limiting the scope of an OSN app in Higher Ed settings, feedback from our focus groups suggests that some participants would be in favor of broadening the scope of the OSN than those in favor of a purely professional/academic focus. In addition, as some participants pointed out, there is oftentimes a blurred line in Higher Ed between academic and social networking: A personal relation could eventually turn into a professional one, and vice versa. A social event - such as an alumni mixer could be posted by a university administrator, ostensibly for the purpose of socialization, but could also serve to help students expand their professional network. Adding a means of categorization (e.g., the ability to filter for purely academic or purely social opportunities) could help assuage the concerns of the few participants who said they would like the artifact's OSN to remain entirely professional. One of the important functions of sense of community is fulfillment of needs [61]. Alumni are less likely to need an app focused purely on professional pursuits: i.e. if they already have a job, they would have no use for an app to find professional opportunities. Social networking was cited by alumni participants (as well as several participants who were about to graduate) as a need they would like the design artifact to address. Many participants latched onto a partially-implemented map feature which was designed to find alumni within a user's geographical vicinity. Moving to a new setting after graduation is oftentimes a daunting prospect, especially with the need to seek out and make new social connections. These participants expressed enthusiasm towards the idea of an app that would ease that process by allowing them to make social connections with those in their new location who also identify with the same graduate institution. So, while the OSN artifact was designed to shorten the perceptual distance between community members and their institution, many alumni expressed interest in the app's potential to expand the geographical outreach to wherever they may find themselves after graduation.

The design artifact could build community among alumni if it was introduced and promoted from the moment a student enrolls at a university. Some study participants suggested introducing the artifact to incoming community members at orientation. A strong alumni outreach program views all incoming students as future alumni and begins the alumni outreach process then. Previous research has demonstrated that introducing an OSN as users enter the new community is an effective way to get incoming students to familiarize themselves with the community and develop trust and a sense of identification right away [41].

\subsection{Social Capital}

4.2.1. Structural. With regards to Proposition 2 ("A Mobile OSN with NARS can yield higher levels of social capital"), a slight majority of the participants felt the design artifact could increase a community's 
structural capital (i.e. the number of social ties). Due to the functionality of the peer recommender, the artifact was seen as potentially most effective at increasing structural capital, in that by pushing peer recommendations, the NARS would directly increase the number of network ties in the community. They considered the app as a potential alternative means to finding connections, and a way to expend less time and effort to build social connections.

4.2.2. Relational. A large fraction of the sample felt the design artifact could increase a community's relational capital (i.e. the level of trust and identification, and the norms of reciprocity). Positive response in this regard could be a product of the transactional nature of the ability to post opportunities or receive opportunity recommendations, as well as the transactional nature of graduate school itself. Most graduate students understand that at some point in their academic careers, they can expect to volunteer to help their peers achieve their academic goals because they know they too will eventually need to solicit help from other students to complete their own research. Thus, a setting such as a Higher Ed institution could be an effective target in which a design artifact like Claremont Conversation can facilitate norms of reciprocity by lessening the time and energy investment needed to seek and carry out these transactions.

The study also demonstrated that not only can the artifact increase social capital, but that a baseline level of social capital is needed in order for such an artifact to succeed. A structural baseline was necessary in that participants felt they would not use such an app unless they were certain there would be enough active users such that any content they posted would be seen and responded to in a timely manner. A relational baseline was necessary in that a significant fraction of the sample stated that their level of trust in their peers affected their willingness to participate (e.g., participants who said they trusted one department more than others). Trust and member identification were seen to be more important as precursors to use than as variables that would increase through use of the app.

A prerequisite for a baseline level of trust was most clearly demonstrated in the way in which participants in most of the focus groups sessions independently brought up the idea of being able to trust other users' self-reported skill proficiency. Most focus groups suggested that a future version of the app should let users rate other people a la Uber. Participants suggested implementing endorsements or a peer rating system because they did not know whether they could trust other users' proficiency in their self-reported skills. A prior study of a higher-ed OSN with a NARS that uses users' ratings and rankings of their peers in its recommender logic had proved to be successful at fostering new connections in a community [54]. However, it wasn't discussed - neither in [54] nor in the course of these Focus Groups - whether the knowledge that one could be assigned a rating based on "trustworthiness" would make some reluctant to use such an app. This could be one major downside to implementing such a feature.

4.2.3. Cognitive. However, the conversations within the focus groups also brought to attention the difficulty any OSN - even with support for personal social networking - could have in spreading cognitive social capital between departments. Only a handful of participants felt the design artifact would have an effect on cognitive capital. A potential reason the app was not perceived as capable of facilitating cognitive social capital is because cognitive capital requires an open social forum in which narratives and vision can be shared among the target community members. With the app focused entirely on professional/academic networking, there is no means to facilitate the sharing of cognitive capital. One of the additional features suggested by many of the participants - a newsfeed maintained by the university - is the kind of feature that could promote awareness of other community members' activities and accomplishments and build the cognitive aspect of social capital.

Furthermore, the factors that allow community members to develop a shared vision are difficult to transfer from department to department. The shared narratives that lay the foundation for a shared vision are difficult to propagate throughout every subunit of a community if the design artifact exclusively focuses on formal social networking to the exclusion of the casual. Due to the level of siloization in many graduate schools, the student experiences are unique from department to department, and the cognitive social capital that exists in one department may well be specific to that department alone. For example, an app that allows students to share their narratives and awareness of their activities might help build cognitive capital in a highly focused department (e.g. Art or Music) where all students are on essentially the same career path. But their shared vision would be unique to their department, and awareness of their activities most likely will not translate to higher cognitive social capital in a department such as Information Systems or Math, in which students have completely different requirements and activities from one another, and a wide range of possible career paths and focuses. The focus group conversations suggest cognitive social capital is a resource that might be easier to build within departments rather than between. 


\subsection{Knowledge Exchange and Combination}

With regards to Proposition 3 ("A Mobile OSN with NARS can yield greater exchange and combination of knowledge"), number of the participants felt that the design artifact could increase the effectiveness of a community's social capital. Some participants felt that the artifact could yield greater exchange and combination of knowledge. This was dependent on how much social capital they believed to be in the community; namely trust, identification, and shared vision. Many participants said that they would be more willing to believe content posted via the app is reliable and relevant because they trust their fellow peers, or because knowing that every user is a member of the same community would make them more willing to trust those users. Features related to trust (e.g., peer endorsements or recommendations) were common participant suggestions. Features that establish social presence (e.g., profile pictures) were also common suggestions, recalling prior research that demonstrated that higher levels of social presence help to establish trust [7]. The belief that other users understand the same struggles as they do (i.e., coursework, research, publications, etc.) also helps establish a willingness to trust the quality of their posted content.

Their willingness to use the app was also dependent on the quality of the peers and opportunities recommended to them. Participants expressed reluctance to keep the app installed on their mobile devices if they felt the NARS was pushing inaccurate or far-too-frequent recommendations. Thus, many of the suggested features included filters to limit the amount and kinds of push notifications the app could send them. While the version of the artifact used in the focus groups used simple match criteria on shared skills or research interests, a version in a real-life setting might use more specific criteria, such as through collaborative filtering using a Pearsoncorrelation coefficient or other formulations that are not triggered as frequently. [54] developed such a recommender system using similar ratings on blog postings as the criteria for peer recommendations.

\section{Conclusions and Discussion}

Claremont Connection is an expository instantiation of an Information System Design Theory (ISDT), in which an artifact constructed around a mobile Online Social Network (OSN) and a Pushbased Notification and Recommendation System (NARS) - whose principles of form and function were justified by Social Capital theory - for the purpose of improving the scholarly community of a Higher Ed institution. This study serves as a starting point to the implementation, development, and deployment a similar design artifact with the same form and function in a Higher Ed setting. In addition to the above-noted key features of the Claremont Connection application (app), several additional features that could be incorporated into the form and function of the design artifact for use in different but similar settings were suggested by study participants during focus group sessions. The focus group also illumined several variations in which a similar app could leverage different kinds of social capital, e.g. a feature for finding alumni within a user's general vicinity could help build structural social capital. Or a similar app could be deployed within a single department on campus to focus on building cognitive social capital. These features enhance the app's degree of artifact mutability. A subset of these features could be added to the design artifact to fit in with any academic unit in which it is deployed. Different departments or schools within different universities might vary with respect to demographics, subject matter, academic focus, etc.

\section{Limitations and Future Research}

A key limitation with the study was the short amount of time in which participants were able to experiment with the design artifact. An online scholarly community would normally contain content that community members had collected, reflected on, and published over the long-term course of several semesters. It normally takes more time for a new OSN to blossom into a meaningful, content-rich community. If given more time than two hours in a focus group session, users would be able to use the features more and develop more nuanced perceptions of perceived value, interactions with social capital, and knowledge combination and exchange.

Furthermore, when the scenarios are scripted, or users create content during structured exercises where they imagine a hypothetical community-wide rollout of the design artifact, usage patterns might differ with respect to how users would approach such an artifact in an uncontrolled setting. In this study, volunteer users were asked to imagine the design artifact was in wide use amongst the wider alumni community. The temporary quality of profiles and opportunities posted for testing purposes may have influenced participants' perceived value of the system. Additionally, it may be difficult for users to trigger push notifications in a small group. If more meaningful, content-rich, and longer lasting profiles or opportunities were posted in a 
widely-used artifact, users might feel more compelled to explore and create more of their own content.

A future research project could deploy a similar app (with the additional features suggested by this focus group) over a longer period - at least a semester - in a Higher Ed setting. This study is a starting point that demonstrates the potential for a novel system design that can be deployed in a Higher Ed setting for a future long-term quantitative study.

\section{References}

[1] Abel, F., Bittencourt, I. I., Costa, E., Henze, N., Krause, D., \& Vassileva, J. (2010). Recommendations in online discussion forums for E-learning systems. IEEE Transactions on Learning Technologies, 3(2), 165-176.

[2] Acquisti, A., \& Gross, R. (2006). Imagined Communities: Awareness, Information Sharing, and Privacy on the Facebook. Privacy Enhancing Technologies Lecture Notes in Computer Science. 6th International Workshop, PET 2006, Cambridge, UK, June 28-30, 2006, Revised Selected Papers, 4258, 36-58.

[3] Adler, P.S., \& Seok-Woo K. (2002, January). Social Capital: Prospects for a New Concept. The Academy of Management Review. 27(1), 17-40.

[4] Adomavicius, G., \& Tuzhilin, A. (2005). Toward the next generation of recommender systems: A survey of the stateof-the-art and possible extensions. IEEE Transactions on Knowledge and Data Engineering, 17(6), 734-749.

[5] Beaudoin, C. E. (2008, April). Explaining the relationship between Internet use and interpersonal trust: Taking into account motivation and information overload. Journal of Computer-Mediated Communication, 13(3). 550-568.

[6] Beem, C. (1999). The necessity of politics: Reclaiming American public life. Chicago: University of Chicago Press. $311+$ xiv pages.

[7] Biocca, F., Harms, C., \& Burgoon, J. K. (2011). Toward a more robust theory and measure of social presence: review and suggested criteria. Presence: Teleoperators \& Virtual Environments, 12 (5), 456-480.

[8] Bobadilla, J., Hernando, A., \& Arroyo, A. (2011). Elearning experience using recommender systems. Proceedings of the 42nd ACM Technical Symposium on Computer Science Education, Dallas, TX, USA. 477-481.

[9] Bock, G., Zmud, R. W., Kim, Y., \& Lee, J. (2005). Behavioral intention formation in knowledge sharing: Examining the roles of extrinsic motivators, socialpsychological forces, and organizational climate. MIS Quarterly, 29 (1), 87-111.

[10] Buder, J., \& Schwind, C. (2012). Learning with personalized recommender systems: A psychological view. Computers in Human Behavior, 28(1), 207-216.

[11] Burt, R. S. (1992). Structural holes: The social structure of competition. Cambridge, Mass: Harvard University Press.

[12] Calvert, G., Mobley, S., \& Marshall, L. (1994). Grasping the learning organization. Training and Development, 48(6), 38-43

[13] Chiu, C., Hsu, M., \& Wang, E. T. G. (2006). Understanding knowledge sharing in virtual communities:
An integration of social capital and social cognitive theories. Decision Support Systems, 42(3) 1872-1888.

[14] Coleman, J. S. (1994). Foundations of social theory. Cambridge, MA: Harvard University Press,

[15] Donath, J., \& Boyd, D. (2004). Public displays of connection. BT Technology Journal, 22(4), 71-82.

[16] Ellison, N. B., Steinfield, C., \& Lampe, C. (2007). The benefits of Facebook "friends:" Social capital and college students' use of Online Social Network sites. Journal of Computer-Mediated Communication, 12(4), 1143-1168.

[17] Fernandez, R. M., Castilla, E. J., \& Moore, P. (2000). Social capital at work: Networks and employment at a phone center. American Journal of Sociology, 105(5), 1288-1356.

[18] Field, J. (2003). Social capital, London: Routledge.

[19] Fukuyama, F. (1995). Trust: The social virtues and the creation of prosperity. New York : Free Press, 1995

[20] Gabbay, S. M., \& Zuckerman, E. W. (1998). Social capital and opportunity in corporate R\&D: The contingent effect of contact density on mobility expectations. Social Science Research, 27(2), 189-217.

[21] Granovetter, M. S. (1995). Getting a job: A study of contacts and careers (2nd ed.). Chicago: University of Chicago Press.

[22] Gregor, S., \& Jones, D. (2007). The anatomy of a design theory. Journal of the Association for Information Systems, 8(5), 312-335.

[23] Haan, S., Cowley, S., Forbes, A., Griffiths, P., \& Maben, J. (2003). The M-C-M' cycle and social capital. Social Science Medicine 56(5), 1061-72.

[24] Hansen, M. T. (1998). Combining network centrality and related knowledge: Explaining effective knowledge sharing in multiunit firms. Working paper (Harvard University. Graduate School of Business Administration. Division of Research). Boston: Division of Research, Harvard Business School.

[25] Hargadon, A., \& Sutton, R. I. (1997). Technology brokering and innovation in a product development firm. Administrative Science Quarterly, 42: 716-749.

[26] Hill, T. R., \& Roldan, M. (2005). Toward third generation threaded discussions for mobile learning: Opportunities and challenges for ubiquitous collaborative environments. Information Systems Frontiers, 7(1), 55-70.

[27] Jacobs, J. (1961). The Death and Life of Great American Cities. New York: Random House.

[28] Kavanaugh, A., Reese, D., Carroll, J., \& Rosson, M. (2005). Weak ties in networked communities. The Information Society, 21(2), 119-131.

[29] Kobayashi, T., Ikeda, K. i., \& Miyata, K. (2006). Social capital online: Collective use of the Internet and reciprocity as lubricants of democracy. Information, Communication \& Society, 9(5), 582-611.

[30] Kraut, R. E., Fish, R. S., Root, R. W., \& Chalfonte, B. L. (Eds.). (1990). Informal communication in organizations: Form, function, and technology. Beverly Hills: Sage Publications.

[31] Lin, N., \& Dumin, M. (1986). Access to occupations through social ties. Social Networks, 8(4), 365-385.

[32] McGrath, J. E., \& Hollingshead, A. B. (1994). Groups interacting with technology: ideas, evidence, issues, and an agenda. Thousand Oaks, CA: Sage Publications. 
[33] Nahapiet, J., \& Ghoshal, S. (1998). Social capital, intellectual capital, and the organizational advantage. Academy of Management Review, 23(2), 242-266.

[34] Nonaka, I. (1996), "The knowledge creating company". In Starkey, K. (Ed.), How Organizations Learn, Thompson, London, pp. 18-23.

[35] North, D. C. (1990). Institutions, institutional change and economic performance. Cambridge, England: Cambridge University Press.

[36] Pennar, K. (1997). "The tie that leads to prosperity: The economic value of social bonds is only beginning to be measured." Businessweek, 3557, 153-155.

[37] Preece, J. (2000). Online communities: Designing usability, supporting sociability. New York: John Wiley \& Sons.

[38] Putnam, R. D. (1993). The prosperous community: Social capital and public life. American Prospect, 13, 35-42.

[39] Raacke, J., \& Bonds-Raacke, J. (2008). MySpace and Facebook: Applying the uses and gratifications theory to exploring friend-networking sites. Cyberpsychology \& Behavior: The Impact of the Internet, Multimedia and Virtual Reality on Behavior and Society, 11(2), 169-174.

[40] Raban, D. R., Ricken, S. T., Sukeshini, A., Grandhi, Laws, N., \& Jones, Q. (January 05, 2009). Hello Stranger! A Study of Introductory Communication Structure and Social Match Success. Proceedings of the 42nd Hawaii International Conference on System Sciences - 2009, 1-9.

[41] Ractham, P. 2008. Improving sense of community: An action research on social software artifact for a graduate university. Doctoral Dissertation. Claremont Graduate University.

[42] Räsänen, P., \& Kouvo, A. (2007). Linked or divided by the web? Internet use and sociability in four European countries. Information, Communication \& Society, 10(2), 219-241.

[43] Rhodes, J., Lok, P., Yu-Yuan, R. H., \& Fang, S. C. (2008). An integrative model of organizational learning and social capital on effective knowledge transfer and perceived organizational performance. Journal of workplace learning, 20(4), 245-258.

[44] Robert, L. P., Dennis, A. R., \& Ahuja, M. K. (2008). Social capital and knowledge integration in digitally enabled teams. Information Systems Research, 19(3), 314-334.

[45] Roda, C., \& Thomas, J. (2006). Attention aware systems: Theories, applications, and research agenda. Computers in Human Behavior, 22(4), 557-587.

[46] Sander, T. H. (2002). Social capital and new urbanism: leading a civic horse to water? National Civic Review, 91(3), 213-221.

[47] Schafer, B. J., Konstan, J. A., \& Riedl, J. (2001). Ecommerce recommendation applications. Data Mining and Knowledge Discovery, 5(1-2):115-153.

[48] Seibert, S. E., Kraimer, M. L., \& Liden, R. C. (2001). A social capital theory of career success. Academy of Management Journal, 44(2), 219-237.
[49] Sein, M., Henfridsson, O., Purao, S., Rossi, M., Lindgren, R. (2011). Action Design Research. MIS Quarterly, 35(1), 37-56.

[50] Shah, D. V., Kwak, N., \& Holbert, R. L. (2001). "Connecting" and "disconnecting" with civic life: patterns of internet use and the production of social capital. Political Communication, 18(2), 141-162.

[51] Sirisaengtaksin, K. 2016. An Information Systems Design Theory for a Notification and Recommender Mobile App for Educational Online Discussion. Doctoral Dissertation. Claremont Graduate University.

[52] Suthers, D., Kar-Hai, C., \& Joseph, S. ( 2009). Bridging Socio-Technical Capital in an Online Learning Environment. Proceedings of the 42nd Hawaii International Conference on System Sciences - 2009, 1-10

[53] Terveen, L., \& McDonald, D. W. (2005). Social matching: A framework and research agenda. $A C M$ Transactions on Computer-Human Interaction, 12(3), 401434.

[54] Thoms, B. 2009. Expanding Learning and Social Interaction Through Intelligent Systems Design: Implementing a Reputation and Recommender System for the Claremont Conversation Online. Doctoral Dissertation. Claremont Graduate University.

[55] Tsai, W. \& Ghoshal, S. (1998). Social capital and value creation: The role of intrafirm networks. Academy of Management Journal 41(4), 464-476.

[56] Uslaner, E. M. (2000). Social capital and the net. Communications- ACM, 43(12), 60-65.

[57] Valenzuela, S., Park, N., \& Kee, K. F. (2009). Is there social capital in a social network site?: Facebook use and college students' life satisfaction, trust, and participation. Journal of Computer-Mediated Communication, 14(4), 875901.

[58] Walls, J. G., Widmeyer, G. R., \& El, S. O. A. (2004). Assessing information system design theory in perspective: How useful was our 1992 initial rendition? Journal of Information Technology Theory and Application, 6(2), 43-58. [59] Wasko, M. M., \& Faraj, S. (2005). "Why should I share? Examining social capital and knowledge contribution in electronic networks of practice." MIS quarterly, 2(1), 935-57. [60] Wellman, B., Haase, A. Q., Witte, J., \& Hampton, K. (2001). Does the Internet increase, decrease, or supplement social capital? Social networks, participation, and community commitment. American Behavioral Scientist, 45(3), 436-455. [61] Wright, S. P. 2004. Exploring Psychological Sense of Community in Living-Learning Programs. Doctoral Dissertation. University of Maryland.

[62] Yli-Renko, H., Autio, E., \& Sapienza, H. J. (June 01, 2001). Social capital, knowledge acquisition, and knowledge exploitation in young technology-based firms. Strategic Management Journal, 22, 587-613.

[63] Zhang, Y. and Hiltz, SR (2003). "Factors that Influence Online Relationship Development in a Knowledge Sharing Community." Proceedings of AIS Americas Conference on Information Systems. 